\title{
Isolated circumpapillary coloboma with normal optic disc: a rare presentation
}

\author{
Ramesh Venkatesh 지 , Pranjal Mishra, Harshita Nahata, Naresh Kumar Yadav
}

Department of Retina and Vitreous, Narayana Nethralaya, Bangalore, India

\section{Correspondence to} Dr Ramesh Venkatesh; vramesh80@yahoo.com

Accepted 16 December 2021

Check for updates

(c) BMJ Publishing Group Limited 2021. No commercial re-use. See rights and permissions. Published by BMJ.

\begin{tabular}{|l|}
\hline To cite: Venkatesh R, \\
Mishra P, Nahata H, \\
et al. BMJ Case Rep \\
2021;14:e247353. \\
doi:10.1136/bcr-2021- \\
247353 \\
\hline
\end{tabular}

\section{DESCRIPTION}

A 31-year-old man was referred by a general ophthalmologist for retinal examination owing to an abnormal-looking disc in the right eye. His presenting visual acuity in the right eye was $6 / 12$, N6 with a refraction of -2.00 DS, -0.75 DC @ $100^{\circ}$ and in the left eye was $6 / 6$, N6 with a refraction of -1.00 DS, - 0.5 DC @ $170^{\circ}$. His intraocular pressure and anterior segment findings were normal. The left eye fundus was unremarkable. The right eye fundus showed an excavated lesion, extending temporally just sparing the fovea in the peripapillary region. The optic disc margins were not clearly visible on examination. The remainder of the peripheral retina and retinal vasculature was normal. No intraretinal or subretinal fluid was noted at the macula. The initial impression was that of an optic disc coloboma without maculopathy. Other differential diagnoses which were kept in mind were large optic disc secondary to glaucoma, morning glory disc anomaly and even peripapillary staphyloma. The patient had no systemic medical conditions. Clinical examination findings were documented under pupillary dilatation using the conventional colour fundus photograph with Topcon, TRC-50Dx imaging system with $50^{\circ}$ field of view. Other imaging tests such as optical coherence tomography and fluorescein angiography with Spectralis, Heidelberg machine and ultrasound B scan were done. The imaging tests confirmed the presence of a normal healthy optic disc within a circumpapillary retinochoroidal coloboma and intrachoroidal cavitation below its inferior margin. No detachment of the intercalary membrane was noted (figure 1).

Coloboma of the fundus is caused by defective closure of the embryonal fissure. ${ }^{1}$ Various theories have evolved for the optic disc coloboma to come into existence. These include impaired closure of the optic fissure, defective migration of neural crest cells and/or due to PAX-2 gene mutation leading to abnormal astrocytic differentiation. ${ }^{2}$ The visual acuity is affected when coloboma involves disc and fovea, or is complicated by occurrence of retinal detachment, choroidal neovascular membrane, cataract, amblyopia due to uncorrected refractive errors, etc. ${ }^{3}$ As per Ida Mann's classification, ${ }^{4}$ there are seven types of fundal colobomas: type 1 , coloboma extending above the optic disc; type 2, coloboma extending up to superior border of disc; type 3, coloboma extending below the lower border of disc; type 4, coloboma involving the disc only; type 5 , coloboma present below the disc with normal retina above and below the coloboma; type

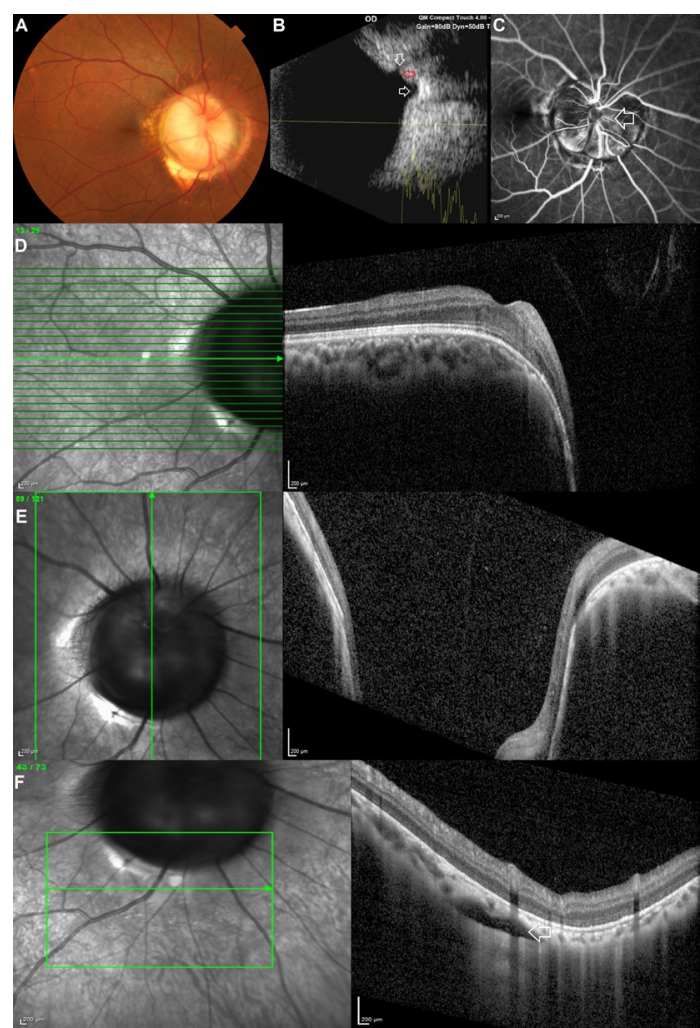

Figure 1 (A) Multimodal imaging of the right eye in a case of isolated circumpapillary coloboma: colour fundus image of the right eye shows an excavated lesion at the posterior pole in the peripapillary area suggestive of coloboma, extending temporally just sparing the fovea in the peripapillary region. The margins of the optic disc cannot be clearly made out. No intraretinal or subretinal fluid was noted at the macula. (B) Ultrasound B scan shows the excavated lesion suggestive of coloboma (white arrows) surrounding the optic nerve head (red arrow). (C) Fluorescein angiography of the right eye shows the surface capillaries on the optic nerve head surface surrounded by the colobomatous area. (D) OCT scan of the right eye through the disc and macula shows the normal foveal contour and outer retinal layers at the fovea. Excavated lesion is noted just adjacent to it showing the margin of the coloboma. (E) vertical OCT scan passing through the centre of the coloboma shows an elevated region within the coloboma suggestive of the optic nerve. (F) Horizontal line enhanced depth imaging OCT scan passing below the inferior margin of the coloboma shows a hyporeflective area in the choroid with normal, intact overlying retinal pigment epithelium suggestive of intrachoroidal cavitation (white arrow). OCT, optical coherence tomography. 
6 , pigmentation present in the periphery; and type 7 , coloboma involving only the periphery. In general, the disease severity is depicted from the most severe (type 1) to the least (types 6 and 7). A type 1 anomaly is expected to have the worst vision, while the type 7 anomaly is expected to have normal vision. The gap in this classification is that the type of disc involvement within the choroidal coloboma was not specified. The classification by Gopal et al divided these eyes into six types based on location and disc involvement in the coloboma. ${ }^{5}$ In types $1-3$, the fundal coloboma did not reach the optic disc, while in types $4-6$, the disc was enclosed within the coloboma. Poor vision was more often seen with types 4-6. The lacuna in this classification was that isolated optic disc coloboma was not considered. In our case, there was an isolated circumpapillary coloboma sparing the fovea with a normal optic disc enclosed within it and mild visual acuity loss. Such a variety of coloboma may be classified as type 1 coloboma as per Ida Mann's classification (as the upper margin of the coloboma is above the optic disc margin) and as type 4 coloboma as per Gopal et al classification (optic disc lies inside the coloboma and appears normal). According to both of these

\section{Learning points}

- Isolated circumpapillary coloboma is a rare description of fundal coloboma.

- Ancillary retinal imaging can help in identifying the optic nerve and differentiating an optic disc coloboma from a circumpapillary coloboma.

- Vision is affected primarily due to involvement of the fovea and optic disc in fundal colobomas. classifications, there should have been severe visual acuity loss. In our case, visual acuity was minimally affected as the fovea was spared by the coloboma, and there was a healthy normal optic disc within it. Our case fits into a rare description of fundal coloboma, which we label as 'isolated circumpapillary coloboma'. This description has not been previously reported in literature to the best of our knowledge.

Contributors RV: conceptualisation of the data and paper writing: PM and HN: data acquisition; NKY: review of the manuscript.

Funding The authors have not declared a specific grant for this research from any funding agency in the public, commercial or not-for-profit sectors.

Competing interests None declared.

Patient consent for publication Consent obtained directly from patient(s)

Provenance and peer review Not commissioned; externally peer reviewed.

Case reports provide a valuable learning resource for the scientific community and can indicate areas of interest for future research. They should not be used in isolation to guide treatment choices or public health policy.

\section{ORCID iD}

Ramesh Venkatesh http://orcid.org/0000-0002-4479-9390

\section{REFERENCES}

1 Duke-Elder S. Anomalous closure of embryonal cleft-typical colobomata. in: system of ophthalmology. St Louis: CV Mosby company 1963:456-88.

2 Dutton GN. Congenital disorders of the optic nerve: excavations and hypoplasia. Eye 2004; 18:1038-48.

3 Lingam G, Sen AC, Lingam $\mathrm{V}$, et al. Ocular coloboma-a comprehensive review for the clinician. Eye 2021;35:2086-109.

4 Mann I. Developmental abnormalities of the eye. London: Cambridge University Press, 1937: 65-103.

5 Gopal L, Badrinath SS, Kumar KS, et al. Optic disc in fundus coloboma. Ophthalmology 1996:103:2120-7

Copyright 2021 BMJ Publishing Group. All rights reserved. For permission to reuse any of this content visit

https://www.bmj.com/company/products-services/rights-and-licensing/permissions/

BMJ Case Report Fellows may re-use this article for personal use and teaching without any further permission.

Become a Fellow of BMJ Case Reports today and you can:

- Submit as many cases as you like

- Enjoy fast sympathetic peer review and rapid publication of accepted articles

- Access all the published articles

- Re-use any of the published material for personal use and teaching without further permission

Customer Service

If you have any further queries about your subscription, please contact our customer services team on +44 (0) 2071111105 or via email at support@bmj.com.

Visit casereports.bmj.com for more articles like this and to become a Fellow 